\title{
APROXIMACIÓN A MECANISMOS DIGITALES EN AMAZONÍA ECUATORIANA PARTIENDO DE MUESTREO EN LA UNIVERSIDAD ESTATAL AMAZÓNICA
}

\section{APPROACH TO DIGITAL MECHANISMS IN THE ECUADORIAN AMAZON BASED ON SAMPLING AT THE AMAZONIAN STATE UNIVERSITY}

\author{
William Ojeda ${ }^{1}$
}

Recibido: 2019-01-10 / Revisado: 2019-03-19 / Aceptado: 2019-04-01 / Publicado: 2019-07-01

Forma sugerida de citar: Ojeda, W. (2019). Aproximación a mecanismos digitales en amazonía ecuatoriana partiendo de muestreo en la Universidad Estatal Amazónica. Retos de la Ciencia, 3(7), 56-73. https://doi.org/10.53877/rc.3.7.20190701.06

\section{RESUMEN}

Se reflexiona sobre nuevos mecanismos de consumo y acceso a información usados por jóvenes, tomando como punto de partida el resultado de estudio realizado a estudiantes de nivelación, segundo semestre de 2018 de la Universidad Estatal Amazónica, Ecuador; en el que se observa un claro desplazamiento de los medios convencionales, mediante nueva instrumentación digital en auge; coyuntura ésta que plantea nuevos mecanismos, lenguajes y hábitos de consumo informativo. Se persigue el objetivo de identificar interés de los jóvenes en torno a determinadas informaciones y los mecanismos mediante los cuales acceden a la misma. El alcance del estudio es limitado por cuanto se circunscribe a la región amazónica, y específicamente al grupo de alumnos que ingresaron en el período e institución señalados líneas antes. En lo metodológico se hace un abordaje bidimensional, por cuanto se desarrolla un trabajo documental a los fines de valorar los distintos enfoques teóricos relacionados con reflexiones fundadoras y los aportes más recientes en materia de comunicación en el marco del proceso globalizador. Así como también se realiza una fase experimental mediante encuesta por muestreo. Entre los resultados del análisis se toma nota del redimensionamiento de las relaciones interpersonales promovido por la era digital de este tiempo, cuando topan la escena novedosos procedimientos que obligan a resemantizar y resignificar los conceptos y los mensajes; con un redimensionamiento del espacio público de

\footnotetext{
1 Doctor en Estudios del Desarrollo. Profesor de la Universidad Estatal Amazónica. Ecuador, E-mail: williamojeda2012@gmail.com
} 
encuentro en las interrelaciones sociales, donde lo transitorio surge como característica esencial de una nueva plaza pública de socialización, pero ahora virtual, a modo de esfera pública de paso que gradualmente se convierte en escenario cotidiano. Se concluye que existe una inclinación mayoritaria en los jóvenes que inician los estudios universitarios en Ecuador, específicamente en la región amazónica, a informarse de los acontecimientos que consideran relevantes a través de la internet y plataformas digitales, en detrimento de los medios convencionales de información que han sido paulatinamente desplazados de la atención.

Palabras clave: comunicación, redes digitales, plaza pública, medios convencionales.

\section{ABSTRAC}

It reflects on new mechanisms of consumption and access to information used by young people, taking as a starting point the result of the study conducted among undergraduate students, second semester of 2018 at the Amazonian State University, Ecuador, which shows a clear shift from conventional media, through new digital instruments on the rise, a situation that poses new mechanisms, languages and information consumption habits. The objective is to identify young people's interest in certain information and the mechanisms through which they access it. The scope of the study is limited because it is restricted to the Amazon region, and specifically to the group of students who entered the period and institution indicated above. The methodological approach is two-dimensional, since a documentary work is developed in order to evaluate the different theoretical approaches related to founding reflections and the most recent contributions in the field of communication within the framework of the globalization process. An experimental phase is also carried out by means of a sample survey. Among the results of the analysis, note is taken of the redimensioning of interpersonal relations promoted by the digital era of this time, when new procedures that force the resemantization and re-signification of concepts and messages hit the scene; with a redimensioning of the public space of encounter in social interrelations, where the transitory emerges as an essential characteristic of a new public square of socialization, but now virtual, as a public sphere of passage that gradually becomes an ordinary stage. It is concluded that there is a majority inclination among young people starting university studies in Ecuador, specifically in the Amazon region, to inform themselves about events they consider relevant through the Internet and digital platforms, to the detriment of conventional information media that have been gradually displaced from attention.

KEYWORDS: communication, digital networks, public square, conventional media.

\section{INTRODUCCIÓN}

Cuando se aborda el debate inacabado sobre el fenómeno de la globalización y su incidencia determinante en el tema de la información, en cuanto a su gestión, 
procesamiento, selección y producción de contenidos, se observa la necesidad perentoria de, más allá de lo disruptivo de una hibridación comunicativa tan multifactorial como novedosa, problematizar lo comunicacional en el entendido del riesgo señalado con insistencia por la comunidad académica de alcanzar a constituirse, en la práctica de las grandes corporaciones de medios de información y a través de su interesada representación de la realidad, en un mecanismo de reproducción de la lógica empresarial y la hegemonía capitalista financiera, al servicio de una procurada economía global (Chomsky, 2013).

Trabajos como los de Ricaurte (2018) postulan la aparición de conspicuas dimensiones de dominio a través del rastreo y seguimiento de los gustos, intereses y pareceres de los usuarios de internet en sus distintas aplicaciones y dispositivos. Así, identifica un "capitalismo cognitivo" que alude al aprovechamiento con fines comerciales, incluso políticos e ideológicos, e imposición de una determinada estética y valoración cultural, de los datos y gustos de los usuarios a través de diversas plataformas y con precisión de algoritmos, que inaugura lo que el autor decide en llamar una "economía de la atención", que busca la orientación y manejo monopólico de las subjetividades.

Frente al dilema de tales riesgos propios de la escena global, Martín-Barbero (2014) asume las novedades de las herramientas tecnológicas en una esfera bidimensional que posibilita tanto el eventual avance de la pretensión hegemónica por parte de algunas élites que concentran la producción de contenidos, como al mismo tiempo pondera estas herramientas como eficaces para la emancipación de la masa poblacional permitiendo la construcción de una contrahegemonía que se presenta como una suerte de revancha sociocultural, al echar mano la sociedad a todo su potencial en mediaciones de diverso calibre en el proceso de la comunicación. En esta perspectiva, hay determinación de reconocer la competencia comunicativa de los ciudadanos al tiempo de asumir el proceso de construcción simbólica de lo cultural como un espacio, de suyo, plural.

Otros autores se concentrar en identificar un redimensionamiento de la esfera comunicacional, en la que se impone un mecanismo audiovisual y denota nuevos lenguajes, saberes y sensibilidades, dando lugar a un nuevo ecosistema comunicativo y en la que asumen una especie de reintegración de la imagen en la producción del conocimiento (Velásquez, Rodríguez y Suing, 2018, 34).

Frente a la situación y trascendiendo la coyuntura, otro tanto apunta Martín Serrano $(1987 ; 2006 ; 2011)$ al fundamentar el componente cargadamente social y cultural que tiene la comunicación para la especie humana; actividad comunicativa que necesariamente va más allá de lo instrumental y se ubica en la dimensión de la producción social con todas las consecuencias que esto implica, por lo que es obligante para la discusión universitaria impedir que la comunicación se degrade a mera técnica de control.

Lo cierto es que estamos ante una atmósfera comunicacional que ya no es aquella escena en exclusivo vertical de grandes corporaciones mediáticas y entidades de producción de contenido, sino que, para decirlo con Martín Barbero, asistimos a una modalidad de "convergencia digital" en la que queda superada Revista Científica Retos de la Ciencia. 3(7), pp. 56-73 
aquella unidireccionalidad, y es a su vez reemplazada por una tupida mopa de interconecciones nodales en medio de una alta conectividad, sin obviar ciertas asimetrías como extensión de una realidad social, que replantea así como renueva todo el modelo comunicacional, configuración propia de la sociedad red castellsiana, en la que producción y consumo de contenidos sufren una determinada reconfiguración.

Velásquez, Rodríguez y Suing no observan el tono amenazante del mero riesgo hegemónico, sino que valoran una mayor posibilidad participativa del tiempo que transcurre. Se ratifica que estamos frente a nuevos escenarios y nuevos actores prosumers que participan de la cultura digital, una actitud que describe la producción colectiva para publicar contenidos, (con lo que) más personas pueden expresarse públicamente; es decir, permite construir nuevos modos de participación.

En un sentido más restrictivo y colocando en paréntesis las advertencias ante los peligros hegemónicos asomados, las preguntas tanto central como accesorias que se plantean en el debate de lo comunicacional, buscan evidenciar los sustanciales cambios de hábitos en el consumo informativo, sea este de tipo noticioso o recreacional, lo que da cuenta de una modificación de los procesos en este ámbito. Así, por ejemplo, en el presente estudio se busca con insistencia despejar si ¿un determinado grupo poblacional como el explorado -mediante la técnica de encuestas- compuesto fundamentalmente por lo que Prensky (2001) calificó de nativos digitales, se informan sobre las noticias relevantes de la agenda pública a través de internet o de sus dispositivos móviles, como por ejemplo celulares de alta gama o smartphones, o por el contrario a través de los llamados medios convencionales? Y en el caso de hacerlo a través de dispositivos móviles ¿lo hacen por cuentas o plataformas de redes sociales independientes o por las de los mismos grupos corporativos o grandes cadenas de medios de información?

Nos preguntamos, asimismo, ¿estos chicos encuestados generan, replican o hacen comentarios en torno a cada noticia que consideran relevante? ¿Participan en grupos que reflexionan $u$ opinan sobre tales contenidos informativos? $O$ por el contrario apenas dejan comentarios sueltos en medio de una dimensión de opinión que resulta tan dinámica como efímera.

Cabría preguntarnos, además, si ¿aparece una nueva dimensión de opinión pública, en el marco de la globalización vigente? ¿Ha tenido lugar el surgimiento de nuevos espacios de deliberación? ¿El centro de poder o de control ha cedido superficie y surge una nueva plaza pública? Tal reflexión puede dar lugar, en el marco de la discusión académica en apogeo, a una consideración más detallada sobre un inédito ecosistema comunicativo en el que lo perecedero o fugaz se presenta como característica esencial de una nueva plaza pública de socialización o nodos de relaciones efímeras constituida por una especie de esfera pública de paso (Proaño Zurita, 2017).

El contexto de la presente indagación está enmarcado en los tiempos que corren, con un rasgo particular que lo caracteriza como lo es una suerte de movimiento vertiginoso en el hecho social particularizado por la irrupción tecnológica que, a su vez, y combinada con diversos factores, ha dado lugar a un ambiente 
singular asumido por Ortiz (2004) como un nuevo patrón civilizatorio; en el que buena parte de la población mundial está accediendo a una escala comunicativa global que le concede nuevos parámetros y concepciones de lo cultural, lo artístico, lo estético y con unas posibilidades expandidas como nunca antes en materia de interrelaciones; por lo que en este marco resulta pertinente la expresión a las ciencias sociales (y a la comunicación entre ellas) se les modificó el objeto de estudio.

Tal afirmación se inspira en que asistimos al proceso de transformación más abarcante de lo vivido por la humanidad. La creación masiva en hallazgos y avances tecnológicos al cierre del siglo pasado y durante lo que va del presente ha dado lugar a una tecnocultura, que impone nuevas dinámicas en las interrelaciones personales, comerciales, laborales en una especie de matriz entrecruzada de múltiples posibilidades marcadas por la simultaneidad.

Identificamos un proceso que ha generado la aparición de nuevos escenarios y un variado abanico de dimensiones en los asuntos sociales, desde las referidas relaciones interpersonales, el comercio, la investigación, la docencia, la industria y los sistemas de información, entre otros, que a su vez se particularizan por la posibilidad que ofrece a los usuarios de ser tomados en cuenta, o por lo menos subirse a la tribuna del debate y emisión de contenidos (las plataformas digitales) e interactuar y manifestarse ante un público ilimitado que puede apuntar a la máxima proyección; asunto que permite acicalar la lucha por el reconocimiento que caracteriza, en términos hegelianos, la existencia humana. Con el libre acceso a plataformas diversas y numerosas de redes sociales, se puede exponer, ganar visibilidad, de manera fácil y sencilla ante un auditorio indeterminado, con el potencial de ser global, y así salir del anonimato social impuesto por la estructura social y comunicacional precedente. Este nuevo paradigma es sustantivo y esencial, porque diciéndolo en términos de Castells (2012), la revolución tecnológica a la que aquí se alude, tiene incidencia definitiva en la más humana de las acciones humanas: la comunicación.

\section{MÉTODO Y MATERIALES}

Al pretender aterrizar toda observación, más aún en el campo de las ciencias sociales, cabe decir que delimitar el objeto de estudio y seleccionar las herramientas para abordarlo y analizarlo en profundidad, es siempre dilemático y por demás retador. Representa uno de los momentos cruciales para el cientista, es una tensión espontánea generada entre el investigador y sus variadas inquietudes sobre aquello que le despierta curiosidad intelectual y los mecanismos a utilizar para despejar sus acertijos. A sabiendas que hacerlo con criterio adecuado, es complejo, difícil, pero necesario por cuanto a la postre resultará profiláctico para la conquista del logro indagatorio propuesto.

El presente estudio es una investigación que apela al análisis documental, valorando los distintos enfoques teóricos relacionados con reflexiones fundadoras y los aportes más recientes en materia de comunicación, pero en referencia al 
proceso globalizador aquí mencionado. También investigación documental en lo referido a pensar en la comunicación digital y las tecnologías de la información y la comunicación (TIC) y las repercusiones que, como queda descrito en líneas anteriores, de forma hipotética aquí se sugieren.

Así mismo se plantea un abordaje experimental, bordeando el terreno de la bidimensionalidad, la realización de un diagnóstico mediante la técnica de encuestas para identificar en una población determinada, como lo son un número de 300 individuos cursantes de estudios universitarios (en este caso el curso de nivelación correspondiente al segundo semestre de 2018 -II2018- de la Universidad Estatal Amazónica de Ecuador), el mecanismo mediante el cual este segmento poblacional tomado a modo de muestra estadística, accede a la información de hechos asumidos como relevantes.

La consulta fue realizada del 5 al 9 de noviembre de 2018, en las aulas de clase de la citada casa de estudios, en su campo central ubicado en Puyo, cabecera cantonal de la Provincia de Pastaza, mediante cuestionario con batería de 10 preguntas, en el que se buscó precisar el mecanismo, modo o instrumento mediante el cual los jóvenes que ingresan a la actividad universitaria se informan de asuntos que consideran relevantes, y luego indagar cuál es su actitud en términos de proactividad o no, frente a ese contenido; así como su orientación y disposición a la posibilidad de generar contenido propio. El objetivo principal propuesto a alcanzar es identificar hábitos (en la citada población) en el uso de herramientas o mecanismos digitales para informarse, y de ahí hacerse una opinión en cuanto a eventos concretos de relevancia en el acontecer regional y nacional, así como el uso de tales mecanismos para consumir noticias, entretenimiento, y demás mensajes de variado tópico.

Como se podrá notar en los resultados plasmados seguidamente, la población estudiantil consultada, aunque hace vida escolar en el mismo recinto, no es exclusiva de Pastaza de donde son poco menos del $40 \%$ de los consultados, sino que éstos vienen de distintas provincias del Ecuador, configurando la mayoría de ellos $(74,2 \%)$, un grupo que proviene de las seis provincias de la región amazónica ecuatoriana.

Se prepararon 350 cuestionarios, pero se validaron de manera efectiva 300 de ellos, porque los días cuando se realizó la consulta en las respectivas aulas de los 12 cursos paralelos en los que está repartido el grupo que ingresa a la instancia universitaria amazónica a través del sistema nacional de nivelación (SNN), algunos estudiantes no asistieron; o se presentaron luego del momento de realización de las entrevistas; o llenaron de forma incompleta los cuestionarios. De allí que fueron tres centenas de éstos, los que fueron finalmente validados y procesados para obtener los resultados plasmados en el estudio.

Se trató de un muestreo aleatorio, sin estratificación proporcional, en el que se consultó por igual a toda la población estudiantil que ingresando al citado programa de nivelación en la UEA, asistió a clases los días y horarios del pulso opinático. Por alcance muestral de la población focalizada, en el estudio descriptivo plasmado en estas páginas se asume un margen de error muestral o intervalo de confianza (+) (-) 
$2 \%$, debido a que la cantidad efectiva de individuos encuestados alcanza a cerca del $78 \%$ de la población del referido curso de nivelación.

Vale decir, además, que en el presente trabajo se hace una investigación exploratoria para comenzar a conocer y puntualizar aspectos de este tema en la Provincia Pastaza de la República de Ecuador, así como también es una investigación de característica descriptiva porque permitirá caracterizar una realidad en curso.

El abordaje del planteamiento metodológico coincide con las consideraciones de amplitud y flexibilidad que proclama Castellano (1997), en el sentido que lo metodológico consiste en "... dar coherencia a algunos instrumentos, sin pretender que los mismos se ciñan a un enfoque analítico determinado... no se trata necesariamente de escoger un enfoque u otro y de ser consecuentes con él. Si no más bien de sentirse libres para elegir ideas e instrumentos de cualquier fuente y de mezclarlos como nos parezca, siempre que seamos coherentes" (p. 47).

\section{RESULTADOS}

Especifiquemos a continuación, los resultados concretos obtenidos en la consulta realizada a la muestra de 300 individuos que ingresaron al curso de nivelación del segundo semestre de 2018 en la Universidad Estatal Amazónica.

Los datos generales de la población estudiantil que ingresa al curso de Nivelación, se trabajaron mediante el Sistema de Información Académica y Docente (SIAD), Dirección Informática, de la casa de estudios superiores en cuestión. Cabe destacar que la población estudiantil descrita en la encuesta, la que efectivamente fue validada en el procesamiento de los datos, es mayoritariamente femenina como lo muestra la gráfica siguiente:

Figura 1.

Población consultada, por género:

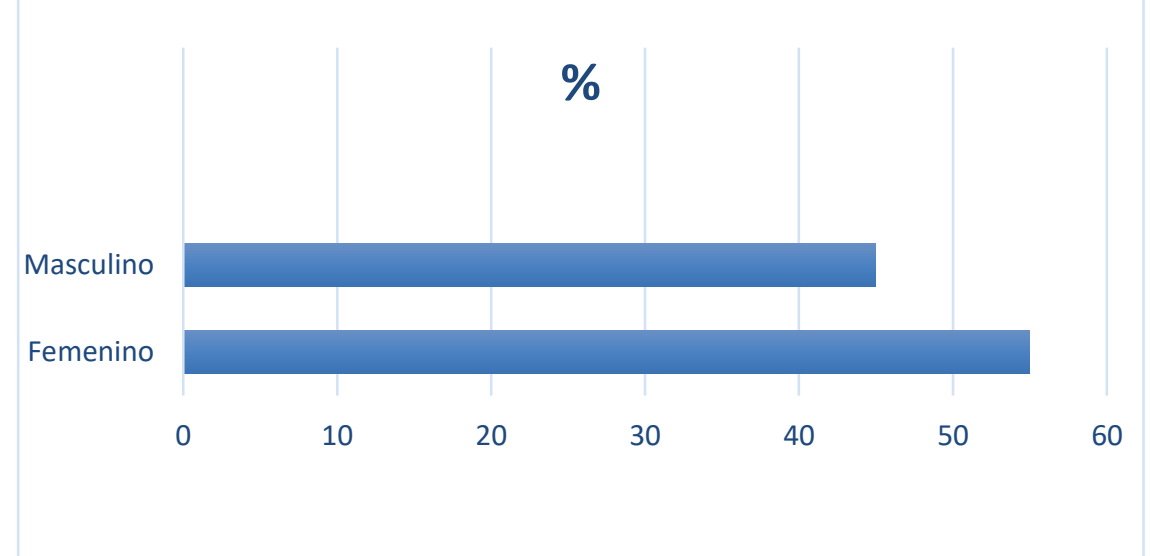

Fuente: encuesta "Hábitos de consumo informativo por parte de estudiantes que ingresan a Nivelación en la Amazonía", UEA II2018-2019.

Elaborado por: Elaboración propia

\section{Edad de los consultados}

La mayoría de los jóvenes que componen la muestra pueden identificarse dentro del concepto de los nativos digitales, en tanto nacieron al cierre del siglo XX y 
comienzos del presente siglo. Esto significa que sus años de vida y aprendizaje han transcurrido durante las dos décadas que va del siglo XXI.

Así el $84 \%$ de los individuos encuestados tienen entre 16 y 21 años. Del resto el $15,4 \%$ se encuentra en la franja entre los 22 y 29 años, y apenas $0,6 \%$ entre los 30 y 35, por lo que es de suyo, una población en su absoluta mayoría por debajo de los 30 años.

Figura 2.

Edad de los encuestados

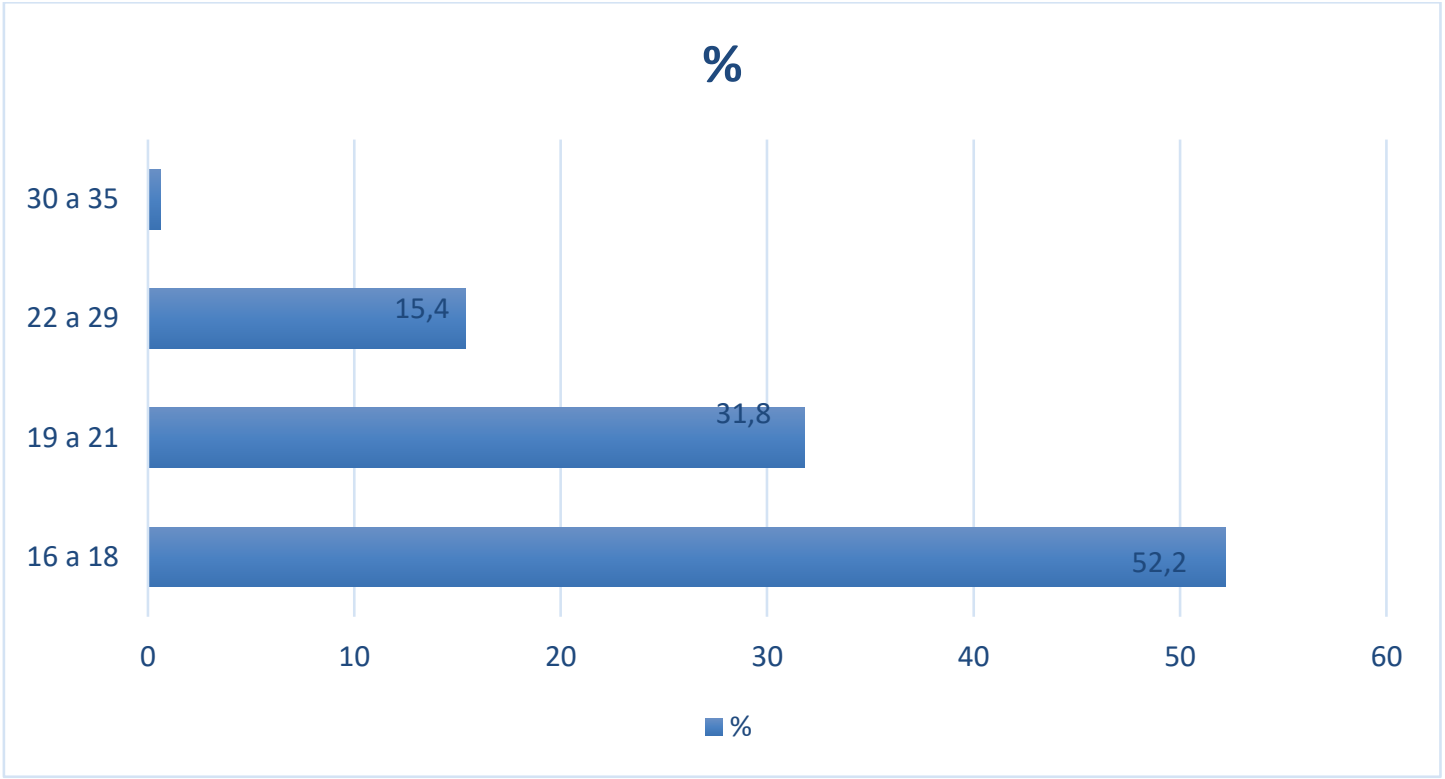

Fuente: encuesta "Hábitos de consumo informativo por parte de estudiantes que ingresan a Nivelación en la Amazonía”, UEA II2018-2019.

Elaborado por: Elaboración propia.

\section{Procedencia}

El $38,6 \%$ de los consultados dijeron provenir de la misma provincia de Pastaza donde se encuentra el campus central de la Estatal Amazónica donde se realizó la consulta. Luego de esta localidad, la respuesta con mayor frecuencia y porcentaje fue Napo con 17,6\%, seguida de Tungurahua con 11,1; Orellana 5,9\%; Morona Santiago con 5,9: Pichincha 5,2; Sucumbíos 2,6; Cotopaxi con 1,9; Chimborazo y Manabí con 1,3\%, mientras que Azuay, Guayas, El Oro, Imbabura, Cañar y Santo Domingo no alcanza el 1\% ninguna de ellas, y juntas representan el 3,9\% como lugar de procedencia de la población consultada.

Ahora bien, reagrupando datos, es significativo señalar que la suma de las seis provincias amazónicas (Pastaza, Sucumbíos, Orellana, Napo, Morona Santiago y Zamora Chinchipe) implica que el $75,2 \%$ de los consultados provienen de la Amazonía ecuatoriana, lo que refleja que la población estudiantil de esta casa de altos estudios es mayoritariamente oriunda de la región donde se encuentra inserta. 
Figura 3.

Procedencia geográfica de los Estudiantes

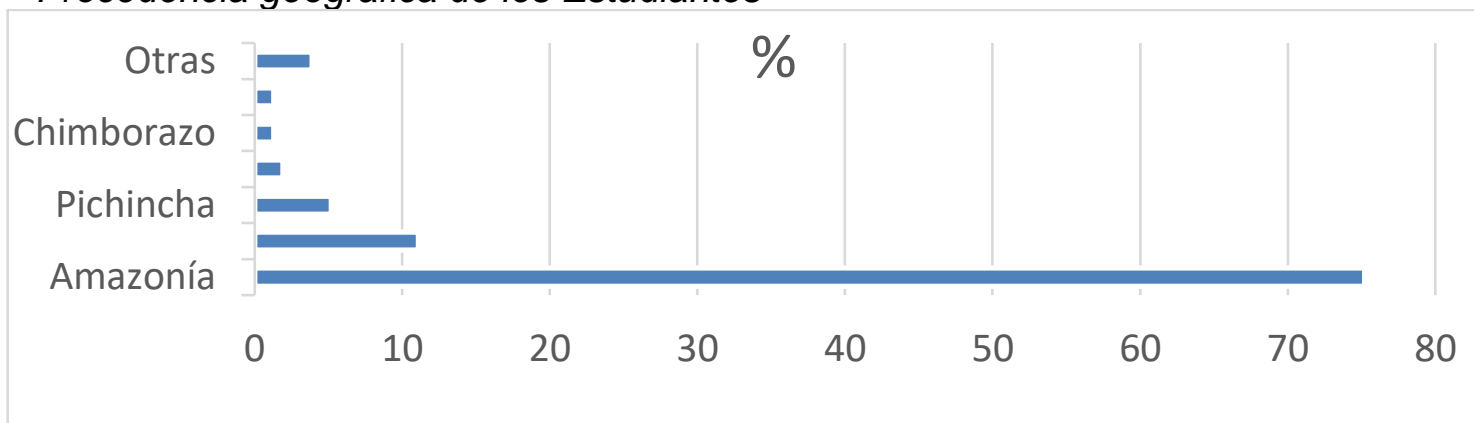

Fuente: encuesta "Hábitos de consumo informativo por parte de estudiantes que ingresan a Nivelación en la Amazonía”, UEA II2018-2019.

Elaborado por: Elaboración propia

\section{Interés por la información}

A la pregunta si el encuestado tiene interés en conocer noticias que considera relevantes del ámbito tanto nacional como internacional, la respuesta es de un peso porcentual por demás contundente, ya que cerca del $94 \%$ dijo estar interesado en acceder a la información, lo cual revela un interés de los estudiantes participantes en el sondeo, por el contenido informativo.

Tal interés da lugar a una validación de la búsqueda investigativa en el presente trabajo, en tanto esa determinación que se evidencia en la Figura 4, deja sentado uno uso de la vida conectada no solo para las interrelaciones personales sino además para el consumo informativo de hechos estimados relevantes por los consultados.

Figura 4.

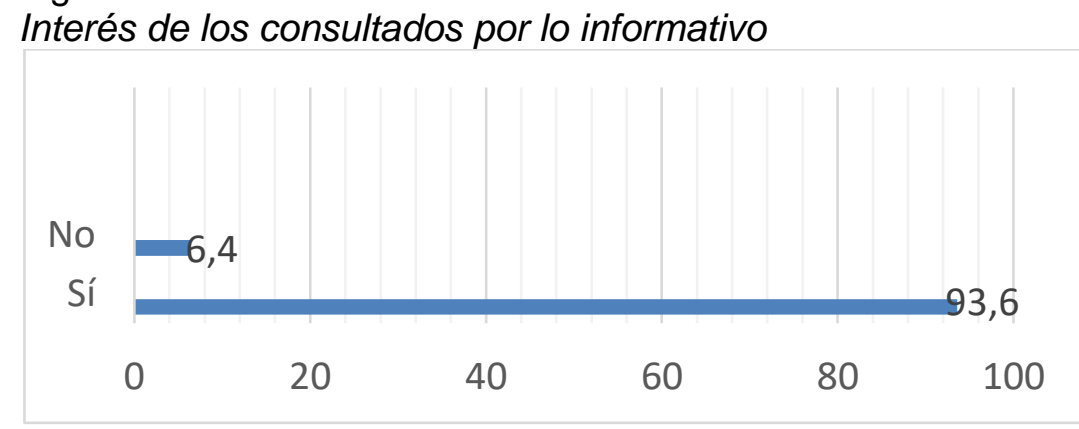

Fuente: encuesta "Hábitos de consumo informativo por parte de estudiantes que ingresan a Nivelación en la Amazonía", UEA II2018-2019.

Elaborado por: Elaboración propia.

\section{Temas de interés}

El cuestionario trató de indagar y precisar cuáles son los temas que despiertan más interés en la población consultada, mediante la pregunta ¿cuál de las fuentes informativas es de tu preferencia?

Se obtuvo en este caso que el asunto que más interesa a los jóvenes de esta consulta es el de la tecnología (26,2\%), luego sigue el tema de sucesos $(19,5 \%)$, 
acontecer político nacional $(19,1 \%)$, acontecimientos internacionales $(14,2 \%)$ y el seguimiento a las instituciones (3\%).

Se reconoce una omisión lamentable en el cuestionario, como es el caso de no haber colocado el ítem de Deportes de forma específica, que a la juventud es un asunto que le suele apasionar y con el que se encuentra, por lo general, directamente vinculado.

Figura 5.

Temas de mayor interés para los jóvenes consultados

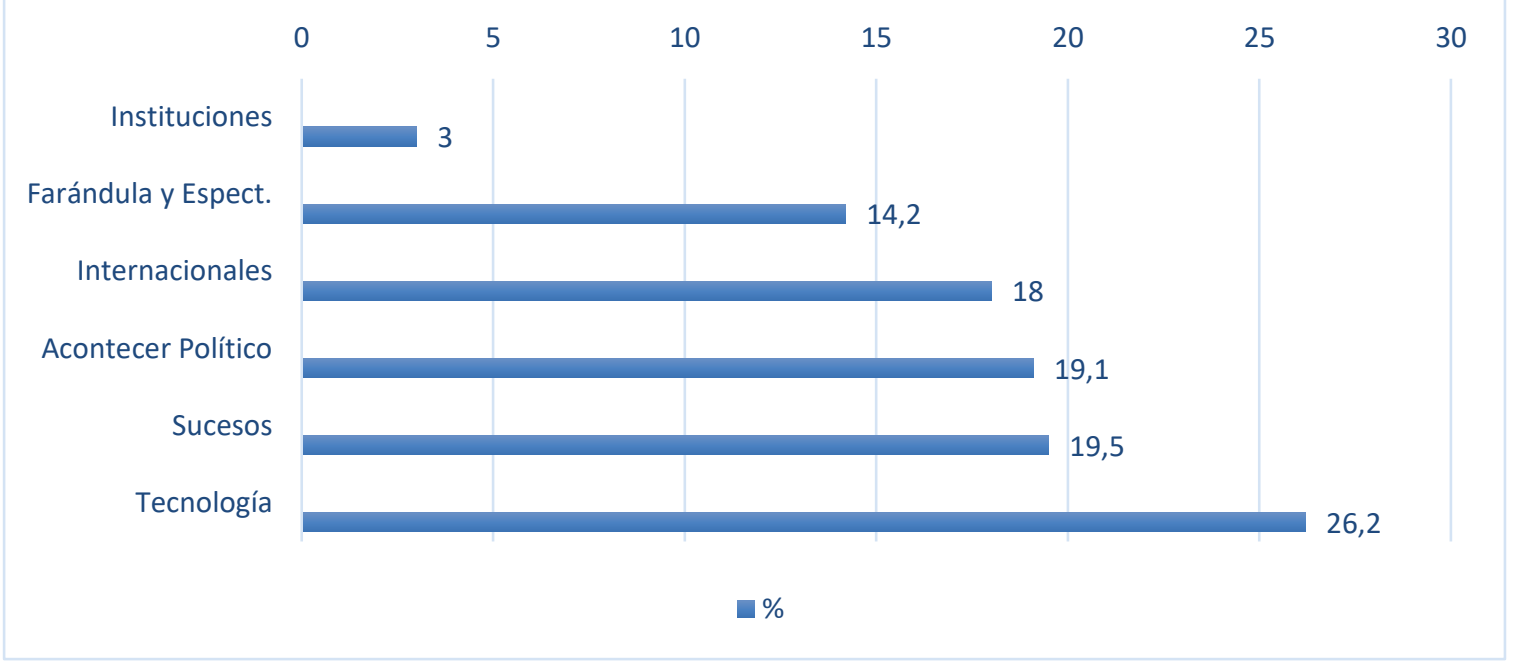

Fuente: encuesta "Hábitos de consumo informativo por parte de estudiantes que ingresan a Nivelación en la Amazonía", UEA II2018-2019.

Elaborado por: Elaboración propia.

\section{Mecanismo a través del cual acceden a la información:}

Con esta pregunta, se aborda el aspecto neurálgico del trabajo que nos ocupa, en el sentido de identificar mediante qué procedimiento, mecanismo o instrumento están mayoritariamente los jóvenes consumiendo información, por lo que este dato resulta crucial en la formulación del planteo investigativo que aquí se aborda.

Es de hacer notar que respondieron por varias opciones, esto es, los jóvenes de la muestra no tienen un único hábito de consumo informativo, sino que apelan a varias modalidades, así que el diseño del cuestionario le permitió a los consultados expresar varias opciones en caso de que no tuviera una única respuesta, pero al mismo tiempo queda claro que para la mayoría de los integrantes de la muestra, la instrumentalización que más usan para acceder a esa información que les llama la atención, los asuntos que consideran relevantes, es la de internet y las redes sociales a través de sus dispositivos móviles.

Esto ocurre a pesar que en la Amazonía para el momento de hacer el cuestionario, segundo semestre de 2018, aún no se ha masificado el servicio de fibra óptica y las operadoras de telefonía celular operan con tecnología 3D, y en algunos casos aún con 2D, siendo que las principales ciudades del Ecuador funcionan masivamente con tecnología celular 4D.

De este aspecto se infiere que, al seguir avanzando el alcance tecnológico y la consiguiente conectividad, la tendencia que arroja el sondeo se profundizará y extenderá, por lo que el consumo de información a través de mecanismos digitales tienda claramente a incrementarse. 
Luego de internet, los teléfonos y dispositivos móviles, sigue la televisión como modalidad utilizada para acceder a información de los hechos relevantes del acontecer noticioso, pero se ubica casi 20 puntos debajo de la internet y redes sociales, lo que marca una brecha digna de considerar, siendo que la segunda mitad del siglo XX fue ampliamente dominada por la televisión en cuanto a audiencia masiva. Luego con un número mucho menor, la radio, que ni siquiera alcanza los 10 puntos. Y finalmente, caso por demás crítico el de los medios impresos, los que apenas superan el 1\%, lo que los acerca a la inexistencia en esta región ecuatoriana.

Llama la atención, que el ítem "conversación directa con familiares", así como con "amigos o relacionados", lo que Chavero (2017) llama "medios informales" de acceso a la información de asuntos públicos, es otro mecanismo mediante el cual los jóvenes se enteran de aquello que estiman relevante.

Figura 6.

Mecanismo de acceso a la in formación

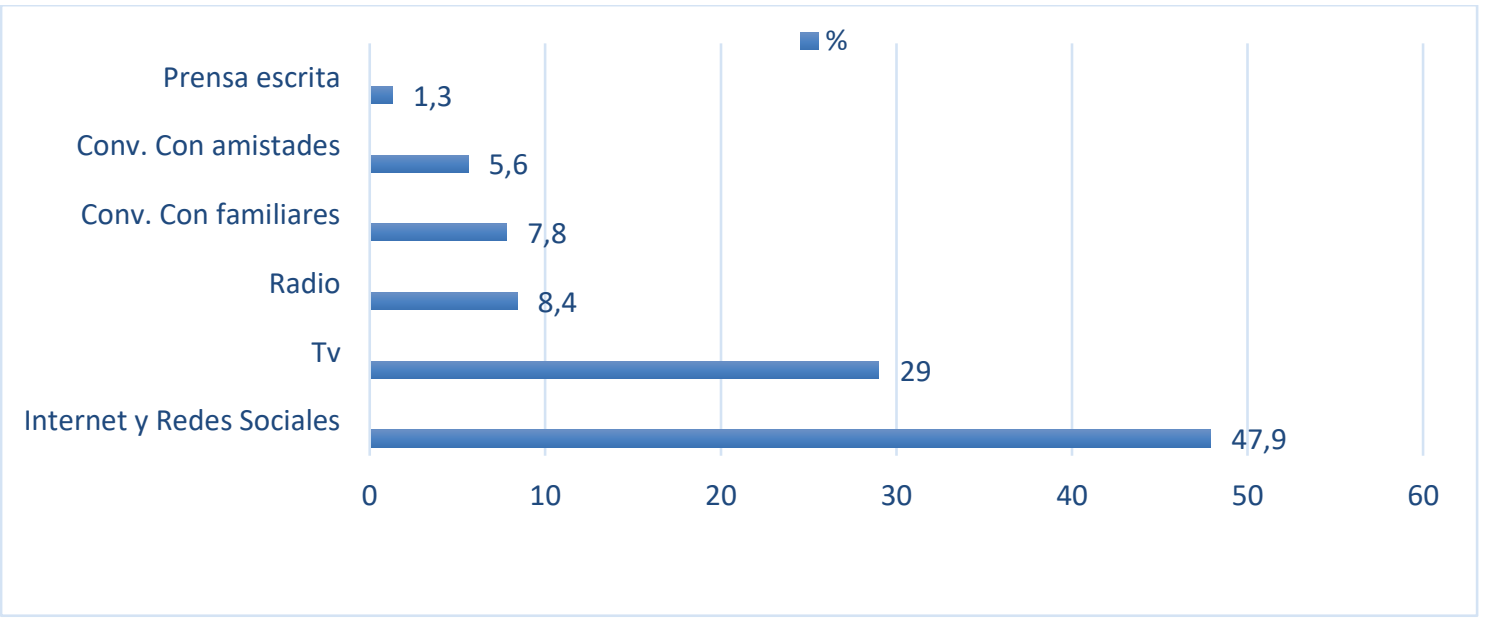

Fuente: encuesta "Hábitos de consumo informativo por parte de estudiantes que ingresan a Nivelación en la Amazonía”, UEA II2018-2019.

Elaborado por: Elaboración propia.

\section{"Hacerse eco" o rebotar información}

A los entrevistados se les preguntó de manera específica, si la información que consideran relevante 0 de su interés, suelen rebotarla o difundirla de alguna manera, a lo que contestaron afirmativamente con un porcentaje apreciable de $87,2 \%$, lo que estadísticamente hablando se puede considerar una acción consistente en este segmento poblacional. En oposición a ese conjunto, un 12,8\% dijo no hacerlo.

Aunque esta sección se concentre en el reporte de los resultados del muestreo, y no obstante líneas más adelante detallamos un poco más el análisis de lo aquí descrito, se subraya en este párrafo que cuando se hace mención a la existencia de "una nueva plaza de encuentro" de las interrelaciones personales, a la que hacemos referencia en estas páginas, su esfera virtual está cargada de componentes informativos diversos que se desplazan desde el ámbito personal, anecdotario, intercambio trivial, hasta el de compartir noticias que se consideran de interés, por lo que el presente dato de una cifra cercana al $90 \%$ que rebota o comparte aquella 
información que resuena en sus intereses, confirma para este estudio tal formulación.

\section{Más allá de un simple reenvío}

Es de interés en el presente análisis saber si la acción de "rebotar" aquella información atractiva para esta población juvenil, se limita al simple hecho de reenviar información que recibieron o a la que accedieron por cualquiera de las vías aquí inidentificadas.

Es así como el cuestionario interrogó a los pesquisados en torno a si realizan algún comentario o agregado a esa información que han decidido re-enviar porque les resulta interesante, y la respuesta fue mayoritariamente $(53 \%)$ positiva, lo que indica que hay una proactividad si no en la creación de contenido propiamente elaborado, ya que cerca del $90 \%$ rebota esa información que recibe y resulta de su interés, sino que además más de la mitad decide agregarle comentarios 0 reflexiones, lo cual supone una actitud resuelta en agregar contenido, una intención mayoritaria de agregar una opinión a la información de la que deciden hacerse eco.

Y lo anterior se infiere habida cuenta que, cuando se les inquirió sobre la producción propia de informaciones; es decir, si protagonizan una realización particular del tipo noticias o información relevante del acontecer nacional, una mayoría del $75 \%$, indicó que no lo hace; con lo que se deja claro que aunque mayoritariamente se comentan informaciones que les llegan, y les agregan su consideración particular, no se ocupan de estar haciendo una elaboración específica de informaciones para ellos divulgar y ser emisores de contenido informativo particular.

\section{Penetración de las grandes corporaciones de comunicación}

Los medios convencionales que vienen perdiendo de manera palpable favoritismo del público, con lo que reducen el monopolio del que hicieron gala desde su aparición hasta la frontera trasvase entre los siglos XX y XXI, podrían al mismo tiempo estar viviendo una suerte de metamorfosis mudándose a la red de redes para tener presencia y copar espacio en la dimensión digital, compensando el que han ido perdiendo en sus mecanismos convencionales.

Aunque cerca del $23 \%$ de los consultados indicó que al navegar por internet y conectarse a sus redes sociales para informarse de lo noticioso, lo hace a través de plataformas independientes, así como grupos colaborativos nuevos e individualidades de credibilidad que transmiten información, es de destacar que el $77 \%$ manifestó que las plataformas a través de las que "se alimenta" de esa información que considera relevante, es la de "medios de comunicación conocidos".

\section{DISCUSIÓN}

\section{Medios convencionales frente a redes digitales}

Lo anterior da pie a varias consideraciones. Puede afirmarse que las grandes corporaciones privadas de la información pierden incidencia, influencia y presencia con sus otrora mecanismos tradicionales de la prensa escrita, la radio y la televisión, aunque esta última aún pervive en el público encuestado en su composición mayoritaria de radicación amazónica; no obstante, igual se encuentra, de acuerdo a las formulaciones de Chavero $(2016 ; 2017)$ en descenso.

Pero al mismo tiempo las empresas mediáticas que se adaptan a la era digital y metamorfosean su instrumental de alcance público abriéndose paso en las plataformas de internet, aún cuentan con capacidad de maniobra, a pesar de que 
hayan tenido que ceder en sus formatos rígidos, códigos imperantes y en un porcentaje de la torta de influencia en el público.

Las líneas anteriores parecen contrastar con la afirmación tajante de Reyes y Molina (2018), para quienes el auge de las redes sociales "parece haber opacado definitivamente a los medios masivos tradicionales"; aun así, lo descrito no hace más que confirmar una evidente situación emergente en la que la tradicional arquitectura en gran medida unidireccional, así como vertical de las grandes corporaciones mediáticas, se encuentra ahora en el terreno sombrío de la obsolescencia.

Por otro lado, y atendiendo a los ritmos distintos en los que avanza esta "ciudadanía digital" y su singular dimensión sociotécnica en tanto que ahora el "estar conectado" representa un imperativo social, ofrece sentido de pertenencia, vale reiterar lo asimétrico del proceso de dicha digitalización en la población, ya que a todas luces transita en un despliegue por capas. Este va ocurriendo a velocidades disímiles, en la medida que avanza y se masifica el acceso a la tecnología y la conectividad en los distintos estratos de pobladores dentro de un país, y entre los distintos países en el contexto internacional.

Dicho lo anterior, y conocidos los resultados más resaltantes del sondeo realizado, el presente caso permite reflexionar sobre si el tan citado fenómeno de la globalización se ha traducido en la práctica en un cambio de hábitos en la instrumentalización del consumo informativo por parte del segmento específico evaluado- de la población.

Las respuestas tabuladas y arriba presentadas permiten evidenciar que existe una nueva forma, por lo menos en el público más joven, de buscar, indagar y acceder a contenido informativo que es de su gusto, interés o considera relevante.

Los medios convencionales de información han sido, unos más que otros, desplazados en un porcentaje elevado por la irrupción tecnológica que han cimentado las plataformas digitales como nueva esfera de tramitación y/o procesamiento informativo.

Pero, de entrada, esto es apenas un punto de partida, por cuanto de inmediato resulta imprescindible considerar y analizar si tal aparición de nuevas formas de consumir (y producir contenido) informativo, trae consigo una modificación en la relación en tanto distanciamiento, como advierte Chavero (2014), entre los usuarios y los medios convencionales, o si se trata tal vez de la válvula de escape a una desconfianza preexistente e in crescendo del ciudadano para con dichos medios tradicionales. Llama la atención, asimismo, lo imperativo de cambios en las pautas de la comunicación convencional, debido a que la información digital atiende, como dice la citada autora, a unas características diferenciadoras que le son propias, como por ejemplo accesibilidad, inmediatez, posibilidad de feedback 0 retroalimentación, velocidad y demás posibilidades que conjugan una aspiración más acabada del evento comunicacional en el sentido de superar la unidireccionalidad de los medios convencionales. Asimismo, hay un desafío mayor por capturar la atención de un público que se encuentra frente a múltiples canales de acceso informativo, en un esquema que Linne (2018) apunta como multitasking en el sentido de cantidad de actividades en simultáneo que atiende hoy el individuo con dispositivos móviles que dejaron de ser teléfonos, para alcanzar el nivel de completos dispositivos portátiles multifunción, en los que concursan proliferación de datos, sonidos, imágenes con diversidad de estímulos audiovisuales que compiten por acaparar la atención del usuario, todo lo cual obliga a un lenguaje más 
recortado, preciso, llamativo, que lo que podía permitirse el ejercicio periodístico y comunicacional en los esquemas de medios convencionales.

Esto porque, como lo resalta Yépez-Reyes (2017), la comunicación actual está caracterizada por la interacción digital, con múltiples nodos de interconexión en una velocidad trepidante, definida como los procesos de comunicación de múltiples vías mediados por la Internet y el uso de las Tecnologías de Información y Comunicación.

Del mismo modo, como no hay consenso sobre el hecho globalizador, no lo hay con el abordaje conceptual de las redes sociales y su papel indicador en una comunicación de nuevo cuño. De allí que resulta necesario a la vez que harto interesante meditar en el debate sustantivo sobre la valoración de las nuevas tecnologías de información y comunicación, en el sentido de ser vistas y asumidas como un bien público que habilita y potencia la comunicación y las relaciones interpersonales, o apenas como un mero instrumento mercantil de grupos privativos que las promueven.

En tal sentido, se comparte en este estudio preocupación con Sierra Caballero (2016) sobre la necesidad de indagaciones llamadas a profundizar en la dimensión sociocultural de la denominada revolución digital. El asunto es una conminación ética y filosófica, a la vez que académica en los ámbitos inter y transdisciplinar.

El investigador español lo expresa con claridad al subrayar la "necesidad de promover conocimiento teórico y empírico... mediante trabajos que aborden desde una visión crítica, social y humanística, el uso y apropiación social de las redes digitales, su impacto en procesos de empoderamiento y desarrollo local" (Sierra Caballero, 2016, 10). Es mandatorio como reto del quehacer científico social, dar un paso o por lo menos una aproximación en ese sentido.

Ocurre, como queda dicho, que en la comunidad académica no existe consenso sobre un juicio de la globalización en la que se está produciendo esta emergencia de nuevas formas comunicativas, siendo el tema globalización como es, fenómeno en curso. Contrario a un criterio unificado, se observa un intenso debate en el que se cruzan los enfoques más disímiles sobre la misma cuestión.

Sin embargo, en las presentes páginas, se asume posición al respeto, por lo que aquí se entiende a la globalización como un evento dinámico, envolvente y multidimensional que, en tanto acontecimiento sistémico, genera importantes transformaciones en diversos escenarios del quehacer social, donde la interdependencia pasa a ser de tal magnitud, que cobra particular relieve.

Pero hemos de admitirlo, el debate apenas comienza. Así, autores aprecian el surgimiento de una cultura mundializada propia de la modernidad-mundo (Wallerstein, 1999), y también identifican consustancial con el evento globalizante, un proceso general de des-territorialización y con ello una posterior reterritorialización, pero resignificada en un abordaje que habla de lo "glocal" y la "glocalidad" como un hecho tangible característico del tiempo presente (Ortiz, 1998; 2004).

\section{Forma distintiva en la producción de contenido}

Sin embargo, surge una corriente de análisis de la comunicación, en cierto modo contrapuesta al desboque globalizante, que revaloriza con fuerza y de manera esencial la localidad y la esfera de lo comunitario como avales potenciadores de esa comunicación de nuevo cuño que empodere y de cabida a todo el potencial del ser humano. Así como también, que posibilite la negociación de sentido e incluso la representación política (Ramos y Sierra, 2014). 
En extensión de esto, se levantan las banderas de los medios comunitarios o populares categorizándolos, tal cual lo afirman Cerbino y Belotti (2016), como "espacios fundamentales para la democratización de la comunicación y para la construcción de una ciudadanía comunicativa".

Dichos autores sostienen que la participación directa de la comunidad en el agenciamiento de tales medios, genera una nueva producción de contenido más relacionada a los intereses y necesidades de ese grupo concreto de la población que los agencia.

Cerbino, no se queda ahí, va más allá aduciendo el gran reto de repensar la comunicación "como una plataforma para replantear las relaciones y posibilidades de constituirse en lazos sociales" (Cerbino, 2018, 28), y sustenta que lo medular está en las condiciones de posibilidad para modificar la producción de contenido, y no ubicar el problema tanto en los contenidos ya producidos, apuntando a una comunicación que ciertamente contenga diversidad y pluralidad de ideas.

En medio de los indicadores poliabarcantes y las dimensiones por demás súper envolventes del hecho globalizador, el autor replica e impugna apostando "por una comunicación del común". Juega a su favor que, en el campo de las políticas públicas, se ponderan como virtuosas las prácticas que "privilegian la participación y la deliberación como instrumentos de construcción de una sociedad democrática" (Espinoza, Roth y Waters, 2017, 10), aunque y, además, Cerbino incluso revaloriza la proxémica, el arraigo territorial y espacial en la construcción de una nueva semiótica, una producción de sentido y un nuevo modo de articulación colectivos.

A todas luces estamos ante una nueva dimensión de lo comunicacional, en la que las redes digitales han colocado una impronta particularísima a las interrelaciones sociales, creando un nuevo espacio de confluencia en este caso virtual, en el que ocurren encuentros permanentes y fugaces al mismo tiempo, en una interacción exponencial. Este hecho incorpora cambios en todo sentido, y como subraya Linne (2018), y pone a prueba la adaptabilidad social, por cuanto asistimos a una "crisis de las instituciones de la modernidad, al menos en sus sentidos tradicionales, como el trabajo, las relaciones sexoafectivas y la educación formal $(2018,41)$. Lo que a su vez trae consigo la extensión del reino de la incertidumbre y pérdidas de tradicionales certezas.

Esta esfera es susceptible de ser abordada a la luz de la teoría clásica, así como de los aportes de la producción epistémica actual, sobre nuevas formas, nuevos mecanismos y desconocidos instrumentos de conformación de la opinión por parte de determinados segmentos poblacionales, sobre todo porque muestra señales fácticas de una nueva semiósfera propia de lo que podría ser la emergente "polis del siglo XXI".

\section{CONCLUSIONES}

Existe una inclinación mayoritaria en los jóvenes que inician los estudios universitarios en Ecuador, específicamente en la región amazónica, a informarse de los acontecimientos que consideran relevantes o noticiosos, a través de la internet y plataformas digitales como las redes sociales, en detrimento de los medios convencionales de información que han sido paulatinamente desplazados de la atención de este segmento de la población.

Además, una cifra cercana al $90 \%$ de ellos rebota la información de interés que por distintas plataformas digitales recibe, y más de un $50 \%$ comenta aquella información que considera relevante, con lo que se confirma una actitud proactiva 
tanto en el consumo como en parte de la generación de contenido; sin que esto permita fijar posición sobre la conformación, diversidad, abundancia o profundidad del mismo. Más sí ofrece una señal en atención al concepto de "prosumumers" que bibliografía reciente describe con énfasis.

Esto ocurre en la Amazonía equinoccial, donde aún no se ha masificado el servicio de conexión "on line" mediante fibra óptica, y que para el momento de hacer el sondeo en el público objetivo, segundo semestre de 2018, en sus ciudades más grandes aún tenían el servicio limitado de la tecnología celular 2G y 3G, siendo que en las principales ciudades del Ecuador se opera con 4G y algunas metrópolis de países industrializados se preparan para el uso de la novísima y exponencial $5 \mathrm{G}$. Por lo que se puede inferir, que en la medida que avancen las capacidades tecnológicas y la consiguiente conectividad en esta región de Ecuador, podría acentuarse la tendencia digital en cuanto a acceder a contenido informativo, lo que de suyo supone nuevos hábitos, mecanismos, nuevas formas de consumir y producir información, así como de interrelacionarse entre pares o más allá, con diversos públicos.

Existen distintos enfoques teóricos que en el presente tratan de comprender y explicar la realidad (en materia de comunicación) transversalizada ya no solo por los otrora poderosos y omnímodos más media, sino además por el supuesto empoderamiento que al individuo otorgan las redes sociales, con el surgimiento de un nuevo parámetro de instantaneidad, mayor acceso a información y un ambiente de autonomía en el procesamiento informativo en el marco de una tupida matriz entrecruzada de aplicaciones y plataformas "en línea", más la evidencia de los hechos afirma que la "realidad ha mutado", por lo que se presenta una obligante situación para reflexionar sobre esta nueva dimensión de lo cotidiano y su progreso.

Ante esta "sociedad red" redimensionada que puede calificarse como propia de un "nuevo patrón civilizatorio", resalta lo característico de un inédito espacio de fluidez de las interrelaciones personales enmarcado en un novedoso proceso de socialización en el que surgen unos encuentros o enlaces efímeros, fugaces, perecederos, que reflejan una nueva "plaza pública de encuentro" pero ahora en la dimensión virtual.

Los jóvenes buscan información mayoritariamente a través de las redes digitales y sus dispositivos móviles, pero lo hacen con énfasis a través de plataformas comunicacionales que les resultan conocidas, con lo cual grandes corporaciones mediáticas que progresivamente "se mudan" de la esfera convencional a la nueva atmósfera comunicativa digital, acceden a parte de esa atención del público que antes monopolizaban, pero acceso que ahora será compartido por múltiples canales que copan la atención de los usuarios nóveles en un multitasking de velocidad vertiginosa donde impera lo audiovisual, la diversidad y la inmediatez.

La brecha social se traduce en una asimetría de los distintos estratos de la población en el acceso a la tecnología y a la conectividad, con ello pone ritmos diferenciadores a esa escala del "estar conectados" que se presenta como imperativo relacional en la nueva dimensión sociotécnica.

\section{RECOMENDACIONES}

Resulta interesante continuar la evaluación de los mecanismos mediante los cuales segmentos específicos de la población están haciendo uso para acceder a información, en procura de identificar el que se presenta como un desplazamiento palpable de los medios de información convencionales, al tiempo de asistir al 
surgimiento de un nuevo instrumental en el marco de una tecno-cultura, en la era de las plataformas digitales.

Resulta necesario conjugar exploraciones que se encuentran en desarrollo vinculadas tanto a la globalización como a la comunicación, asuntos que, desde este enfoque, inexorablemente se interconectan, convergen e hibridan; escenario que da lugar a inéditas exploraciones de un proceso dinámico en pleno auge.

Partiendo de las ideas aquí vertidas, resulta necesario hacer un seguimiento dialógico de los patrones de producción-consumo de contenido informativo, por parte del segmento de la población estudiada, de manera tal que permita inferir propensiones tan necesarias como útiles para esclarecer tendencias y parámetros en esta área sensible del quehacer social.

\section{REFERENCIAS BIBLIOGRÁFICAS}

Boczkowski, P. \& Mitchelstein, E. (2017). Smartphone, el aire que respiro. Revista Anfibia. h ps://bit.ly/2hk9M2o.ssep:

Castellano, Hercilio (1997). Planificación: herramientas para enfrentar la complejidad, la incertidumbre y el conflicto, Caracas, CENDES.

Castells, M. (2001). La Galaxia Internet. Barcelona. Areté.

Castells, M. (2009). Comunicación y Poder. Madrid. Alianza Editorial.

Castells, M. (2012). Redes de indignación y esperanza. Los movimientos sociales en la era internet. Madrid. Alianza Editorial.

Cerbino, M. y Belotti, F. (2016). Medios comunitarios como ejercicio de Ciudadanía Comunicativa. Experiencias desde Argentina y Ecuador. Comunicar, (47), pp. 49-56.

Cerbino, M. (2018). Por una comunicación del común. Medios comunitarios, proximidad y acción. Quito. Ediciones Ciespal.

Chavero, P. (2014). Los desahucios en la prensa española: distintos relatos sobre los asuntos públicos. Cuadernos de Información y Comunicación, 19, pp. 271-284.

Chomsky, N. (2013). Razones para la anarquía. Barcelona. Editorial Malpaso.

Departamento de Ciencias de la Comunicación de la Universidad Técnica Particular de Loja (2015). Programa de Investigación en Educomunicación y Cultura Digital: El consumo cultural y el uso de los medios de comunicación en los jóvenes del Ecuador.

Espinoza, B., Roth, A-N. y Waters, W (2017). Introducción. Mundos Plurales (4), 1, pp. 5-6.

Friedman, T. (2006). La tierra es plana. Breve historia del mundo globalizado del siglo XXI, Madrid, MR.

Linne, J.W. (2018). Nomadización, cultura digital y autonomía. Tendencias juveniles a principios del s. XXI. Chasqui. Revista Latinoamericana de Comunicación. (137), Sección Monográfico, pp. 37-52.

Martín-Barbero, J. (1987). De los medios a las mediaciones: comunicación, cultura y hegemonía. Barcelona. GG.

Martin-Barbero, J. (2014). Diversidad en Convergencia. MATRIZes, 8(2), pp. 15-34.

Martín Serrano, Manuel (2006): “¿Para qué sirve estudiar Teoría de la Comunicación ?", Contratexto, (4). Recuperado el 15 de abril de 2019, de http://eprints.ucm.es/13145/

Martín Serrano, M. (1977). La Mediación Social. Madrid. Akal.isepi:

Martín Serrano, M. (2011). Actos ejecutivos y actos expresivos, E-Prints. Complu-tense. Recuperado el 22 de abril de 2019, de http://eprints.ucm.es/13101/

Ojeda, W. (2017). A las ciencias sociales se les modificó el objeto de estudio. Retos de la Ciencia, 1(2), pp. 98-107.

Ortiz, R. (1998). Otro Territorio. Ensayos sobre el mundo contemporáneo, Bogotá, Convenio Andrés Bello.

(2004). Mundialización y Cultura. Bogotá, Convenio Andrés Bello. 
Prensky, M. (2001). Digital Natives, Digital Immigrants, On the Horizon, 9(5), 1-6.

Prensky, M. (2005). Listen to the natives. Educational leadership, 63(4).

Proaño Zurita, J. (2017). Esfera pública de paso: impacto de la cuenta de Twitter de Rafael Correa en la agenda mediática digital y en el debate público, en torno a los proyectos de ley de herencia, plusvalía y diálogo ciudadano (Tesis de maestría). FLACSO Ecuador, Quito.

Ramos, I. y Sierra, F. (2014). Economía política y políticas democráticas de comunicación en América Latina (Dossier). En: Íconos. Revista de Ciencias Sociales. Economía política y políticas democráticas de comunicación en América Latina, 18(49), pp. 912. ISSN: $1390-1249$.

Revista Chasqui (2018). Jóvenes y Cultura Digital. Chasqui. Revista Latinoamericana de Comunicación, 137, Tercera Época; CIESPAL.

Ricaurte, P. (2018). Jóvenes y cultura digital: abordajes críticos desde América Latina. Chasqui. Revista Latinoamericana de Comunicación, (137), pp. 13-28.

Robles, J. (2011). Ciudadanía digital. Una introducción a un nuevo concepto de ciudadano. Barcelona: Universitat Oberta de Catalunya.șep.

Sierra Caballero, F. y Fávaro Garrossini. (2016). Comunicación y Ciudad. La mediación social en la nueva cultura urbana. Barcelona. Gedisa y Ciespal.

Urresti, M., Linne, J. \& Basile, D. (2015). Conexión total. Los jóvenes y la experiencia social en la era de la comunicación digital. Buenos Aires: Grupo Editor Universitario.

Velásquez, A., Rodríguez, C., y Suing, A. (2018). Jóvenes y cultura digitalișpij Siguen los cambios y sin miedos! Chasqui. Revista Latinoamericana de Comunicación, (137), pp. 33-37.

Wallerstein, I. (1999). El moderno sistema mundial. La agricultura capitalista y los orígenes de la economía-mundo europea en el siglo XVI, t. II, México, siglo XXI Editores.

Yépez-Reyes, V. (2017). La estructura rizomática de la incidencia 2.0. Revista PUCE, 104, pp. 131-159. Recuperado el 15 de noviembre de 2018 de http://www.revistapuce.edu.ec/index.php/revpuce/article/view/65/216 